\title{
Solution of problems of ETICS with biocorrosion
}

\author{
Barbora Belániová ${ }^{1,{ }^{*}}$, Nad'a Antošová ${ }^{1}$, and Lucia Šupejová ${ }^{1}$ \\ ${ }^{1}$ Faculty of Civil Engineering in Bratislava, STU, Department of Building Technology, Radlinského \\ 11, 81005 Bratislava, Slovakia
}

\begin{abstract}
To find solutions for maintenance and repair of existing structures ETICS becomes the current another issue of improvement thermal insulation proprieties of external cladding, which need to be answered necessarily till December 2020. Double thermal insulation technology can be achieved by jointly increasing of thermal insulation properties and by repairing surface porosity ETICS. The aim of the research is the analysis of alternative insulation materials in plaster repair by technology "double thermal insulation" ETICS in terms of technology, humidity and temperature conditions in the layers. Technology of double thermal insulation is analyzed in the context with solution biocorrosion surface thermal insulation. In the end of the research there is obtained the data from the comparisson of technology double thermal insulation with different insulation materials expressed by graph. Obtained data can be the basis for decision to choosing a repair, to solution for the structural details of double thermal insulation and also for experimentally assess the lifespan of the double ETICS.
\end{abstract}

\section{Introduction}

In Slovakia the construction of contact insulation is used for approximately 25 years. During the time, various faults appear in older thermal insulation systems, but they do not have to threaten the general function of the structure. The presence of microorganisms in building environments, which according to the analysis threatens the construction from the inside, is also possible [13]. The most common visible thermal contact faults are cracks in each direction, springing-off and mechanical damage, separation of the surface layer from other layers, separation of the reinforcement layer together with the surface plaster from insulation, microorganisms contamination and biological attack of ETICS layers.

The cause of the biological attack of thermal insulation surfaces is not completely known. The research shows that acrylic and silicone plasters are more attacked. This material causes that the drying time of the surface of the plaster on the north and west sides is longer than the silicate plaster. The long-term wet surface of the plaster creates suitable conditions for biofilm formation. According to [13], certain types of microorganisms on the

\footnotetext{
${ }^{1}$ Corresponding author: barborabelaniova@gmail.com
} 
surfaces of building materials produce mycotoxins and play their role within the so - SBS Building Syndrome, who is global problem. Micromycotes act by their physicochemical activities on building materials, including plasters, and degrade them.

Elimination of micro-organisms is the most often used for chemical surface cleaning, but it has a short lifespan and it needs to be repeated regularly. The construction of double thermal insulation could be a lasting solution to this problem. When performing a double thermal insulation, a modern plaster with modified properties that are resistant to microorganisms will be used on the surface. At the same time, meeting the increasing requirements on the Energy Efficiency of Buildings (EEB) by 2020. [2] However, there are several open and unresolved issues in addressing biocorrosion by double thermal insulation. One of them is the risk of the new colonization of "double ETICS" surfaces by microorganisms for using plasters of the original generation and also the threat of microorganisms development in the thermal insulation layer. Such a risk is real in ensuring long-term moisture at the construction site where microorganisms have been recorded on the original surface. The role of long-term research is to investigate the lifespan of the double structure in terms of bio-corrosion, with a new colonization of microorganisms on the surface or renewed colonization in the set of original and new thermal insulation.

\section{Methodology of work}

The research is divided into several parts. The first part describes the principle and rules of implementation technology of double thermal insulation. In the second part, the thermaltechnical and moisture parameters of the double structure are examined for using an insulating layer made of EPS - polystyrene, MW - mineral wool and facades panel PUR polyurethane foam.

The properties of the different insulating materials have been analyzed so that the cooperation condition with the duplicate system is met, which means that the new contact insulation must have the same properties as the original insulation. For comparison, one type of external cladding of a panel apartment building with the most prevalent type of thermal insulation and thickness of thermal insulation was selected. At the same time, the thickness of the new insulation layer was designed to meet the 2020 requirements. [2]

Table 1. Development of standardized requirement of heat transfer coefficient $[2,7]$.

\begin{tabular}{|l|l|l|l|l|}
\hline \multirow{2}{*}{ Building construction } & \multicolumn{4}{|c|}{ Boundary conductance U [W/(m².K) } \\
\cline { 2 - 5 } & $\begin{array}{l}\mathrm{U}_{\max } \\
\text { from 1.2.1997 }\end{array}$ & $\begin{array}{l}\mathrm{U}_{\mathrm{n}} \\
\text { from 1.1.2013 }\end{array}$ & $\begin{array}{l}\mathrm{U}_{\mathrm{N}}=\mathrm{U}_{\mathrm{r} 1} \\
\text { from 1.1.2016 }\end{array}$ & $\begin{array}{l}\mathrm{U}_{\mathrm{N}}=\mathrm{U}_{\mathrm{r} 2} \\
\text { from 1.1.2021 }\end{array}$ \\
\hline External Cladding & 0,46 & 0,32 & 0,22 & 0,15 \\
\hline $\begin{array}{l}\text { Structural floor under } \\
\text { the outside }\end{array}$ & 0,30 & 0,20 & 0,15 & 0,10 \\
\hline
\end{tabular}

The third part evaluates the indicators of the individual double thermal insulation systems with regard to the possibility of moisture in the structure as a potential for development of the microorganisms in the layer. The results are the basis for the proposed methodology for examining the lifespan of the double thermal insulation structure from the perspective of biocorrosion.

\section{Principle and rules of double construction of ETICS}

The essence of double thermal insulation is the addition of another thermal insulation layer, reinforcement layer and new plaster, without deforming the previous layers. The double thermal insulation is currently classified as the usage of a conventional thermal insulation 
system under specific conditions where the original supporting structure and thermal insulation remained [1].

Before realization the construction of the additional ETICS, it is therefore necessary to consider the original structure in accordance with the applicable standards. The requirements for the underlying structure, the properties of the new external thermal insulation composite, the static load bearing capacity of the load-bearing structure and the static design of double insulation are assessed. In addition to other tests, the chemical and physical compatibility of inbuilt and newly applied materials have to be verified. In particular, the mutual compatibility of cement adhesives designed for bonding and dispersion plasters used for old insulation and, in case of inappropriate conclusions, to propose appropriate measures.

\subsection{Original construction of ETICS}

In the research and theoretical assessment, the panel construction system BA-BC, which was realized according to the type of "Prefabricated residential houses of Bauring-Camus T-BA-BC" panel system, was used. It is a typical representative of mass housing construction in Slovakia. The original construction of the solved problem is characterized as a box high-frequency carrier system. Constructional depth of floor is $2700 \mathrm{~mm}$ and the vertical clearance is $2500 \mathrm{~mm}$. The external cladding is made of layered panels which are in the front side and gavel $260 \mathrm{~mm}$ thick. They consist of a $130 \mathrm{~mm}$ indoor reinforced concrete layer reinforced with a welded mesh of a thermal insulation layer, a $50 \mathrm{~mm}$ foam polystyrene and a $80 \mathrm{~mm}$ reinforced concrete layer. The concrete layers are interconnected by a space anchor with diagonals of anticorrosive steel $\varnothing 8 \mathrm{~mm}$ and spacing needles $\varnothing 2$ $\mathrm{mm}[12]$.

\section{Specification of ETICS doubled construction}

It follows from the principles of double thermal insulation that the new insulating material must have the same or better diffusion properties as the original material. The fixation of the new thermal insulation layer of the ETICS is done by means of anchors which ensure the transfer of load in their axes by anchoring them into the supporting layer of the original structure. It is necessary to use anchors with a full-metal screw element, with a plastic spray, when doubling the thermal insulation layer [6]. The maximum thickness of the ETICS thermal insulating layer is limited. The minimum thickness of the new ETICS thermal insulation material is $50 \mathrm{~mm}$. Thickness must be considered by thermo-technical assessment. For greater insulation thicknesses is double thermal insulation need to be taken into account by increased expansion movements, especially at the edges of the ETICS, on the corners [6]. Strength in tension perpendicular to the plane of the new ETICS thermal insulating material for EPS boards min. $100 \mathrm{kPa}$ and in the case of MW boards min. 10 $\mathrm{kPa}$. During realization of double structure it must by observed, the maximum weight of the thermal insulating material, including plasters and adhesives, have to be respected.

\subsection{Alternative solutions of double thermal insulation}

The realization of double thermal insulation was assessed in terms of thermal and technical properties of the structure and humidity regime in three alternative solutions. Alternative I involves the addition of thermal insulating material from EPS in $\mathrm{hr} .80 \mathrm{~mm}$. The bulk density of the polystyrene is $40 \mathrm{~kg} / \mathrm{m}^{3}$ and the diffusion resistance factor is $53.10^{9} \mathrm{~m} / \mathrm{s}$. [8, 11]. In Alternative II, the thermal insulation properties of the mineral wool at a thickness of 
$50 \mathrm{~mm}$ were used in the double insulation. The bulk density of the mineral wool is 45 $\mathrm{kg} / \mathrm{m}^{3}$ and the diffusion resistance factor is $3.310^{9} \mathrm{~m} / \mathrm{s}$. [10, 11]. In Alternative III, the thermal insulation properties of $40 \mathrm{~mm}$ polyurethane foam boards were used in double insulation. The bulk density of the PUR boards is $45 \mathrm{~kg} / \mathrm{m}^{3}$ and the diffusion resistance factor is $4.2510^{9} \mathrm{~m} / \mathrm{s}$. [9, 11]. The detailed composition of each of the double thermal insulation technologies compared is shown in the following table. 2:

Table 2. Composition of double thermal insulation in three alternatives [8-10].

\begin{tabular}{|c|c|c|c|c|c|c|}
\hline \multirow{3}{*}{ no. } & Alternative I & \begin{tabular}{|l|} 
Thickness \\
\end{tabular} & Alternative II & Thickness & Alternative III & Thickness \\
\hline & EPS - polystyrene foam & $t$ & ISOVER TF PROFI- MIN. Wool & $t$ & TPD-polyurethane boards & $t$ \\
\hline & Name of material & $\mathrm{m}$ & Name of material & $\mathrm{m}$ & Name of material & $\mathrm{m}$ \\
\hline 1 & Lime-cement plaster & 0.010 & Lime-cement plaster & 0.010 & Lime-cement plaster & 0.010 \\
\hline 2 & Ex reinforced concrete panel & 0.130 & Ex. reinforced concrete panel & 0.130 & Ex. reinforced concrete panel & 0.130 \\
\hline 3 & Polystyrene foam & 0.050 & Polystyrene foam & 0.050 & Polystyrene foam & 0.050 \\
\hline 4 & Ex reinforced concrete panel & 0.080 & Ex. reinforced concrete panel & 0.080 & Ex. reinforced concrete panel & 0.080 \\
\hline 5 & Lime-cement plaster & 0.010 & Lime-cement plaster & 0.010 & Lime-cement plaster & 0.010 \\
\hline 6 & WEBER.THERM EXCLUSIVE & 0.004 & WEBER.THERM EXCLUSIVE & 0.004 & WEBER.THERM EXCLUSIVE & 0.004 \\
\hline 7 & Polystyrene foam & 0.080 & Polystyrene foam & 0.080 & Polystyrene foam & 0.080 \\
\hline 8 & WEBER.THERM EXCLUSIVE & 0.004 & Reinforcing grid & - & Reinforcing grid & - \\
\hline 9 & Reinforcing grid & - & Undercoating - WEBER 700 & - & Undercoating - WEBER 700 & - \\
\hline 10 & Undercoating - WEBER 700 & - & WEBER.PAS EXCLUSIVE & 0.002 & WEBER.PAS EXCLUSIVE & 0.002 \\
\hline 11 & WEBER.PAS EXCLUSIVE & 0.002 & WEBER.THERM EXCLUSIVE & 0.004 & NEW-THERM ST04 & 0.004 \\
\hline 12 & WEBER.THERM EXCLUSIVE & 0.004 & ISOVER TF PROFI - MIN. WOOL & 0.050 & TPD-polyurethane boards & 0.040 \\
\hline 13 & EPS - polystyrene foam & 0.060 & WEBER.THERM EXCLUSIVE & 0.004 & NEW-THERM ST04 & 0.004 \\
\hline 14 & WEBER.THERM EXCLUSIVE & 0.004 & Reinforcing grid & - & Leno fiberglass fabric R 117 A 1017 & 0.470 \\
\hline 15 & Reinforcing grid & - & Undercoating - WEBER 700 & - & NEW-THERM $\otimes P G M$ & 0.001 \\
\hline 16 & Undercoating - WEBER 700 & - & Weber.MIN & 0.002 & NOVALITH - cover plaster (silicate) & 0.002 \\
\hline 17 & Weber.MIN & 0.002 & & & & \\
\hline
\end{tabular}

From the point of view of the distribution of the temperature field and the humidity regime in the thermal insulation, the values of the thermal field in the cross-sectional area and in the selected critical detail at the level of the window sill were considered and evaluated. The purpose of the assessment was to locate the moisture in the structure of the new structure as a possible source of water supply to residual microorganisms that may be located on the original thermal insulation construction.

Table 3. Thermal-technical and moisture parameters "Double ETICS" with EPS insulation.

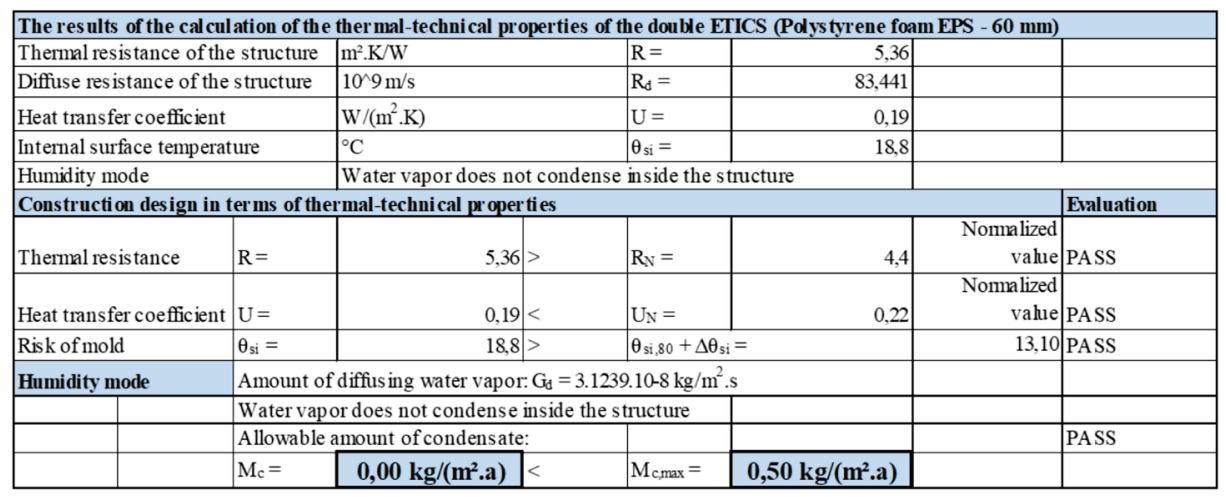

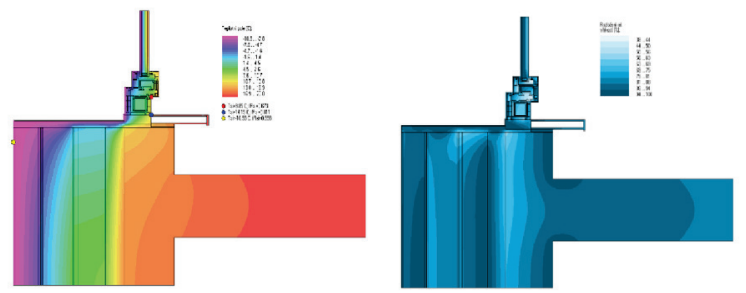

Fig. 1. Layout of temperature and moisture field in double construction (EPS), detail [11]. 
Table 4. Thermal-technical and moisture parameters "Double ETICS" with MW insulation.

\begin{tabular}{|c|c|c|c|c|c|c|c|}
\hline \multicolumn{8}{|c|}{ The results of the calculation of the thermal-technical proper } \\
\hline \multicolumn{2}{|c|}{ Thermal resistance of the structure } & \multicolumn{2}{|l|}{$\mathrm{m}^{2} \cdot \mathrm{K} / \mathrm{W}$} & $\mathrm{R}=$ & 5,16 & & \\
\hline \multicolumn{2}{|c|}{ Diffuse resistance of the structure } & \multicolumn{2}{|l|}{$10^{\wedge} 9 \mathrm{~m} / \mathrm{s}$} & $R_{\mathrm{d}}=$ & 68,774 & & \\
\hline \multicolumn{2}{|l|}{ Heat transfer coefficient } & \multicolumn{2}{|l|}{$\mathrm{W} /\left(\mathrm{m}^{2} \mathrm{~K}\right)$} & $\mathrm{U}=$ & 0,19 & & \\
\hline \multicolumn{2}{|c|}{ Internal surface temperature } & \multicolumn{2}{|l|}{${ }^{\circ} \mathrm{C}$} & $\theta_{\mathrm{si}}=$ & 18,87 & & \\
\hline \multicolumn{4}{|l|}{ Humidity mode } & inside the & ucture & & \\
\hline \multicolumn{7}{|c|}{\begin{tabular}{|l|} 
Construction design in terms of thermal-technical properties \\
\end{tabular}} & Evaluation \\
\hline Thermal resistance & $\mathrm{R}=$ & 5,16 & $>$ & $\mathrm{RN}=$ & 4,4 & $\begin{array}{r}\begin{array}{r}\text { Normalized } \\
\text { value }\end{array} \\
\end{array}$ & PASS \\
\hline Heat transfer coefficient & $\mathrm{U}=$ & 0,19 & $<$ & $\mathrm{U}_{\mathrm{N}}=$ & 0,22 & $\begin{array}{r}\begin{array}{r}\text { Normalized } \\
\text { value }\end{array} \\
\end{array}$ & PASS \\
\hline Risk of mold & $\theta_{\mathrm{si}}=$ & 18,87 & $>$ & \multicolumn{2}{|c|}{$\theta_{\mathrm{si}, 80}+\Delta \theta_{\mathrm{si}}=$} & 13,10 & PASS \\
\hline Humidity mode & \multicolumn{2}{|c|}{ Annual balance sheet: } & & & & & PASS \\
\hline & $\mathrm{M}_{\mathrm{c}}=$ & $0,068 \mathrm{~kg} /\left(\mathrm{m}^{2} . \mathrm{a}\right)$ & $<$ & $\mathrm{Mev}=$ & $8,30 \mathrm{~kg} /\left(\mathrm{m}^{2} . \mathrm{a}\right)$ & & \\
\hline & \multicolumn{3}{|c|}{ Allowable amount of condensate: } & & & & PASS \\
\hline & $\mathrm{M}_{\mathrm{c}}=$ & $0,00 \mathrm{~kg} /\left(\mathrm{m}^{2} . \mathrm{a}\right)$ & $<$ & $M_{c, \text { max }}=$ & $0,50 \mathrm{~kg} /\left(\mathrm{m}^{2} . \mathrm{a}\right)$ & & \\
\hline
\end{tabular}
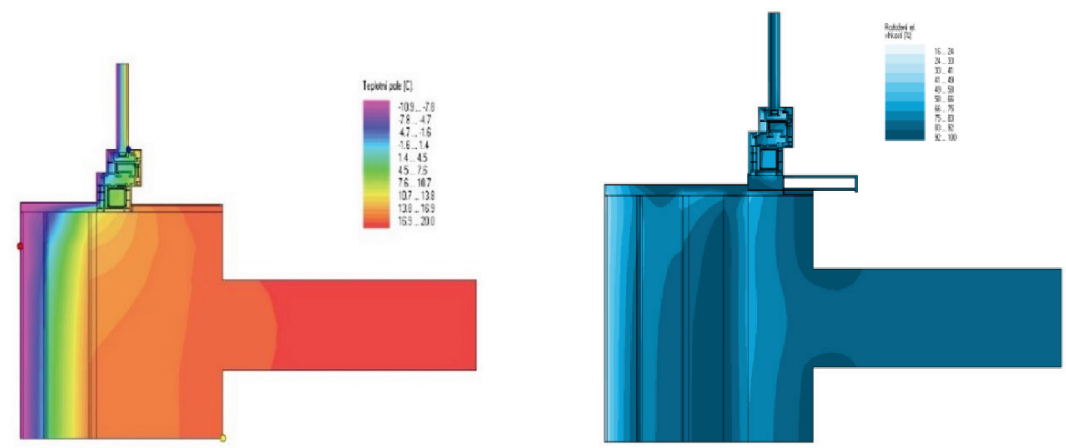

Fig. 2. Layout of temperature and moisture field in double construction (MW), detail [11].

Table 5. Thermal-technical and moisture parameters "Double ETICS" with PUR insulation. (author)

\begin{tabular}{|c|c|c|c|c|c|c|c|}
\hline \multicolumn{8}{|c|}{ The res ults of the calculation of the thermal-technical properties of the double ETICS (Boards TPD - PUR - $40 \mathrm{~mm}$ ) } \\
\hline \multicolumn{2}{|c|}{ Thermal resis tance of the structure } & \multicolumn{2}{|l|}{$\mathrm{m}^{2} \cdot \mathrm{K} / \mathrm{W}$} & $\mathrm{R}=$ & 5,62 & & \\
\hline \multicolumn{2}{|c|}{ Diffuse resistance of the structure } & \multicolumn{2}{|l|}{$10^{\wedge} 9 \mathrm{~m} / \mathrm{s}$} & $\mathrm{R}_{\mathrm{d}}=$ & 145,89 & & \\
\hline \multicolumn{2}{|c|}{ Heat trans fer coefficient } & \multicolumn{2}{|l|}{$\mathrm{W} /\left(\mathrm{m}^{2} \cdot \mathrm{K}\right)$} & $\mathrm{U}=$ & 0,18 & & \\
\hline \multicolumn{2}{|c|}{ Internal surface temperature } & \multicolumn{2}{|l|}{${ }^{\circ} \mathrm{C}$} & $\theta_{\mathrm{si}}=$ & 18,87 & & \\
\hline \multicolumn{2}{|c|}{ Humidity mode } & \multicolumn{6}{|c|}{ Water vapor does not condense inside the structure } \\
\hline \multicolumn{7}{|c|}{ Cons truction design in terms of thermal-technical properties } & Evaluation \\
\hline Thermal resis tance & $\mathrm{R}=$ & 5,62 & $>$ & $\mathrm{R}_{\mathrm{N}}=$ & 4,4 & $\begin{array}{r}\text { Normalized } \\
\text { value }\end{array}$ & PASS \\
\hline Heat trans fer coefficient & $\mathrm{U}=$ & 0,18 & $<$ & $\mathrm{U}_{\mathrm{N}}=$ & 0,22 & $\begin{array}{r}\text { Normalized } \\
\text { value } \\
\end{array}$ & PASS \\
\hline Risk of mold & $\theta_{\mathrm{si}}=$ & 18,87 & $>$ & \multicolumn{2}{|c|}{$\theta_{\mathrm{si}, 80}+\Delta \theta_{\mathrm{si}}=$} & 13,10 & PASS \\
\hline Humidity mode & \multicolumn{2}{|c|}{ Annual balance sheet: } & & & & & PASS \\
\hline & $\mathrm{M}_{\mathrm{c}}=$ & $0,068 \mathrm{~kg} /\left(\mathrm{m}^{2} . \mathrm{a}\right)$ & $<$ & $\mathrm{M}_{\mathrm{ev}}=$ & $8,30 \mathrm{~kg} /\left(\mathrm{m}^{2} . \mathrm{a}\right)$ & & \\
\hline & \multicolumn{3}{|c|}{ Allowable amount of condensate: } & & & & PASS \\
\hline & $\mathrm{M}_{\mathrm{c}}=$ & $0,00 \mathrm{~kg} /\left(\mathrm{m}^{2} . \mathrm{a}\right)$ & $<$ & $\mathrm{M}_{\mathrm{c}, \max }=$ & $0,50 \mathrm{~kg} /\left(\mathrm{m}^{2} . \mathrm{a}\right)$ & & \\
\hline
\end{tabular}



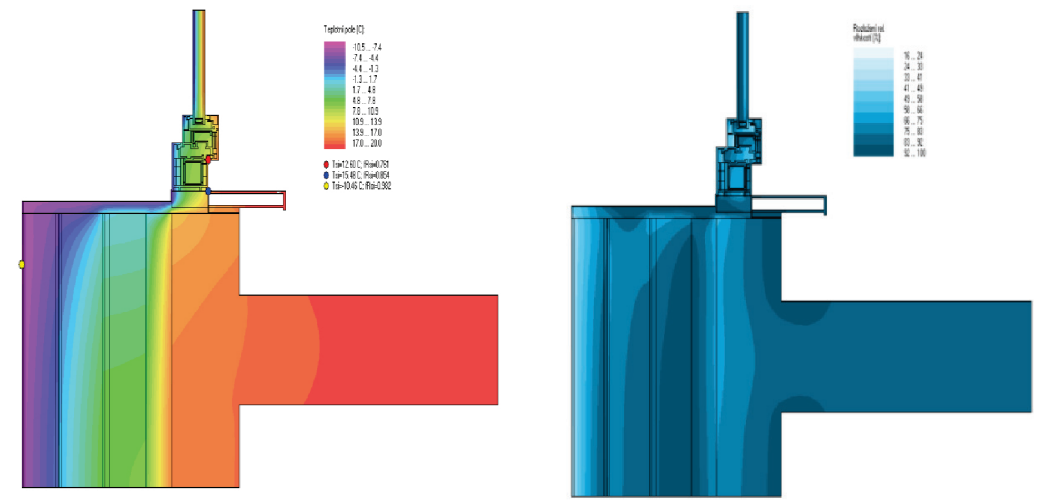

Fig. 3. Layout of temperature and moisture field in double construction (PUR), detail [11].

For the model calculation of the physical properties of the individual alternatives of the double structure, the software was used according to [11].

\section{Discussion and conclusion}

Previous results compare the results obtained with the analysis of the thermal-technical and humidity parameters of the double thermal insulation technologies. The economical parameters (cost of realization of individual technologies) and selected parameters from the point of view of impact on the realization performance were also compared.

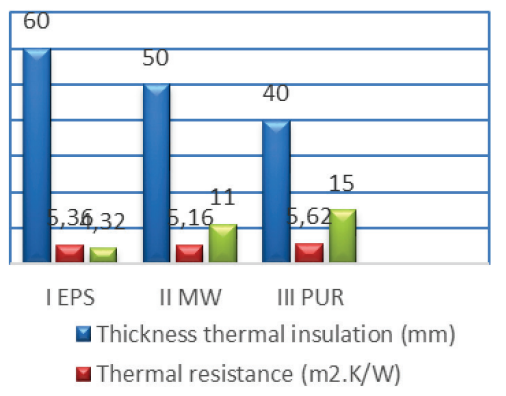

Fig. 4. Comparison of obtained results (thickness, thermal resistance to costs) from analyses.

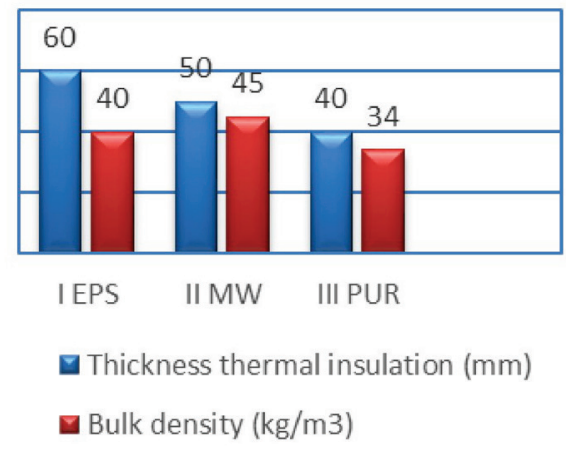

Fig. 5. Comparison of thickness thermal insulation to bulk density from analyzes. 
According to the partial conclusions of the previous research, the best double thermal insulation of PUR boards is shown. However, in terms of input direct costs, it is the least advantageous. During deciding which technology is the most appropriate to use, it is necessary to take into account, except the price, the thickness of thermal insulating material, which in the case of PUR foam comes out at almost the same weight insulation per $1 \mathrm{~m}^{2}$ the thinnest. This is an advantage that can be used, for example, to assess the load of the original thermal insulation. However, the decision-making criterion has to be in terms of the development, recovery of microorganisms and the lifespan of individual technologies. We consider the information founded to be the basis for further research in this field and the processing of the basic methodology of the laboratory lifespan survey which consists of:

- From the preparation of "Double ETICS" samples from existing thermal insulation with attacking algae $(35 \times 35 \mathrm{~cm})$ with multiple types of plaster and ETIC composition to ensure the identity of biological material,

- Simulation of the environment (through SHMU - Slovak Hydrometeorical Institute, detected humidity, precipitation, temperature and wind conditions occurring in a particular area of SR per a multi-year period) and simulation of stress cycles in the climate-chamber Z - Evaluation of samples in terms of the presence, development, recovery of microorganisms under the activated conditions that they need for growth and evolution.

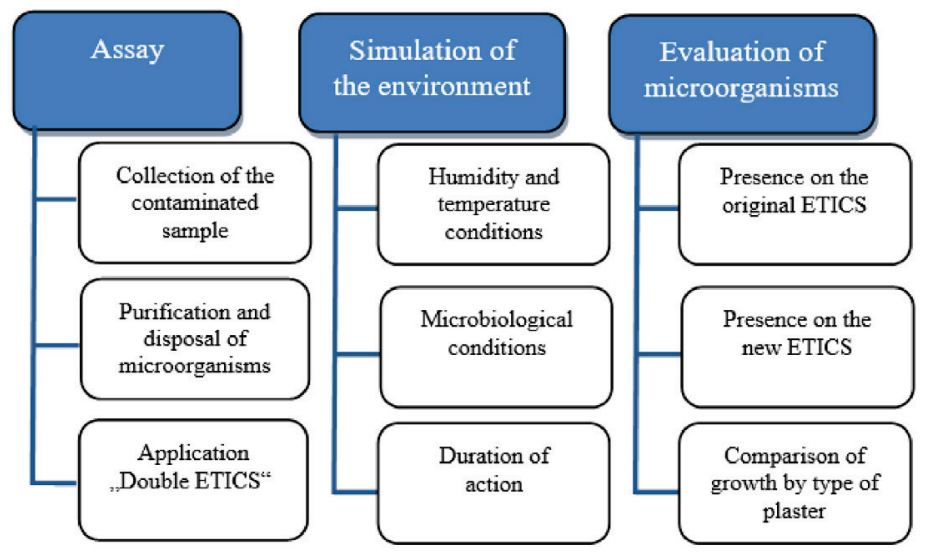

Fig. 6. Method for detecting the life of "bio-corrosion" technology.

We assume that the results of the experimental life test prove the prolonged resistance of thermal insulation against microorganisms and the technology double thermal insulation prevents the development of microorganisms on the original part of the thermal insulation. If the plaster is used on new layers of thermal insulation with biocide protection, we believe that this technology for owners of damaged objects is an interesting solution not only for increasing the thermal protection, but also for the permanent solution of biocorrosion. The double thermal insulation is an effective way of improving the thermal-technical properties of the non-compliant insulated buildings, and simultaneously it helps to solve the problem with algae and microorganisms in the original insulation.

\section{References}

1. STN 73 2901/01 Stage construction external thermal insulation composite system (ETICS) (2015) 
1. STN 73 0540-2 Thermal protection of buildings. Thermal-technical properties of construction structures and buildings

2. Directive of the European Parliament and of the Council no.2012/27/EU on energy efficiency and amending Directives 2009/125/EC and 2010/30/EU and repealing Directives 2004/8!/EC and 2006/32/EC

3. J. Halásková, European trends to reduce road accidents. Proceedings from the seminar VUT FAST (2007)

4. H. Viner, R. Sinhal, S. Parry, Review of UK Skid Resistance Policy. PIARC International Symposium „SURF2004“ (Toronto, 2004)

5. A. Vojtěšek, Comparative measurement of dynamic devices for the measurement of road surface friction coefficients. Proceedings from the seminar VUT FAST (2007)

6. Outside Contact-Imaging Systems ETICS 01 -2014 - Technical Rules of the Guild for Insulation of Buildings of the Czech Republic, O.S.

7. Technical form EPS FS 70, Producer of ISOVER - Saint-Gobain Construction Products, s.r.o. Available on http://www.isover.sk

8. Technical form TPD PUR30/40, Producer of PCC Moravia. Available on http://www.new-therm.cz

9. Technical form MW-ISOVER TF PROFI, Producer of ISOVER - Saint-Gobain Construction Products, s.r.o. Available on http://www.isover.sk

10. Thermal Reviews Software Svoboda Area and Heat Student Edition.

11. Z. Sternová et. al., Renovation of apartment buildings. Massive housing construction until 1970. (Jaga group, Bratislava, 2002)

12. J. Švajlenka, M. Kozlovská, T. Pošiváková, and E. Čonková, Indoor analysis of environment in buildings, Chemical journal, - The official journal of Czech Chemical Society. 